\title{
THE SUMMER MEETING IN POUGHKEEPSIE
}

The forty-eighth Summer Meeting of the Society and the twentyfourth Colloquium were held at Vassar College, Tuesday to Thursday, September 8-10, 1942. The Mathematical Association of America met on Monday morning and afternoon. The Institute of Mathematical Statistics met Wednesday morning and jointly with the Society Tuesday afternoon and Wednesday afternoon. About three hundred persons attended the meetings among whom were the following one hundred ninety-eight members of the Society:

C. R. Adams, R. B. Adams, R. P. Agnew, Warren Ambrose, R. C. Archibald, K. J. Arnold, L. A. Aroian, K. J. Arrow, W. L. Ayres, F. E. Baker, G. M. Bareis, Walter Bartky, Stefan Bergman, Felix Bernstein, Henry Blumberg, J. W. Bower, R. W. Brink, A. B. Brown, J. A. Bullard, F. J. H. Burkett, Hobart Bushey, J. H. Bushey, S. S. Cairns, W. D. Cairns, B. H. Camp, W. B. Carver, W. F. Cheney, D. E. Christie, J. A. Clarkson, L. W. Cohen, Nancy Cole, Esther Comegys, T. F. Cope, A. H. Copeland, Richard Courant, C. C. Craig, J. H. Curtiss, D. R. Davis, F. F. Decker, R. P. Dilworth, J. L. Doob, M. E. Elveback, Benjamin Epstein, Paul Erdös, W. K. Feller, M. M. Flood, L. R. Ford, R. M. Foster, K. O. Friedrichs, R. E. Fullerton, Abe Gelbart, B. P. Gill, R. E. Gilman, Michael Goldberg, Cornelius Gouwens, H. S. Grant, R. E. Greenwood, T. N. E. Greville, C. C. Grove, V. G. Grove, E. J. Gumbel, Theodore Hailperin, D. W. Hall, O. G. Harrold, O. C. Hazlett, C. M. Hebbert, G. A. Hedlund, E. R. Hedrick, Edward Helly, L. S. Hill, Einar Hille, T. R. Hollcroft, M. W. Hopkins, G. M. Hopper, Harold Hotelling, S. E. Hotelling, E. M. Hull, C. C. Hurd, Witold Hurewicz, W. A. Hurwitz, Dunham Jackson, Fritz John, R. A. Johnson, A. W. Jones, B. W. Jones, F. B. Jones, H. A. Jordan, Wilfred Kaplan, Irving Kaplansky, Edward Kasner, S. Y. Keyser, B. F. Kimball, J. R. Kline, A. E. Landry, R. E. Langer, G. A. Larew, Solomon Lefschetz, Charles Loewner, C. I. Lubin, Eugene Lukacs, N. H. McCoy, C. C. MacDuffee, Saunders MacLane, H. F. MacNeish, H. B. Mann, Morris Marden, A. J. Maria, D. H. Maria, M. H. Martin, M. P. Martin, A. E. Meder, F. H. Miller, E. B. Mode, E. C. Molina, Deane Montgomery, C. N. Moore, E. M. Morenus, Valdimir Morkovin, Richard Morris, D. S. Morse, Marston Morse, M. E. Munroe, Otto Neugebauer, A. V. Newton, K. L. Nielsen, R. E. O'Connor, E. G. Olds, Oystein Ore, Gordon Pall, C. R. Phelps, H. B. Phillips, Everett Pitcher, Hillel Poritsky, G. B. Price, M. H. Protter, A. L. Putnam, S. E. Rasor, L. L. Rauch, Mina Rees, C. F. Rehberg, W. T. Reid, R. G. D. Richardson, J. F. Ritt, M. S. Robertson, H. A. Robinson, S. L. Robinson, R. E. Root, R. A. Rosenbaum, J. H. Rosenbloom, P. C. Rosenbloom, Raphael Salem, Hans Samelson, Arthur Sard, F. E. Satterthwaite, L. J. Savage, Henry Scheffé, Abraham Schwartz, G. E. Schweigert, R. G. Simond, A. J. Smith, Gertrude Smith, Ernst Snapper, Virgil Snyder, D. E. Spencer, V. E. Spencer, Abraham Spitzbart, A. H. Sprague, H. W. Steinhaus, J. J. Stoker, R. R. Stoll, A. H. Stone, S. R. R. Struik, Otto Szász, Gabor Szegö, J. D. Tamarkin, C. J. Thorne, A. W. Tucker, J. W. Tukey, D. F. Votaw, Abraham Wald, R. M. Walter, Louis Weisner, B. A. Welch, M. E. Wells, E. T. Welmers, George Whaples, H. S. White, G. T. Whyburn, R. L. Wilder, S. S. Wilks, W. L. G. Williams, E. W. Wilson, Jack Wolfe, Jacob Wolfowitz, E. R. Worthington, C. H. Yeaton, J. W. T. Youngs, Antoni Zygmund. 
The Colloquium Lectures on the subject Topology of manifolds were delivered by Professor R. L. Wilder of the University of Michigan on Tuesday morning and afternoon and Wednesday and Thursday mornings. The presiding officers at the four lectures were, in order, President Marston Morse, Professor Solomon Lefschetz, Professor G. T. Whyburn, and Vice President J. D. Tamarkin.

There was a short business meeting Wednesday morning at the beginning of the general session, President Marston Morse presiding. Secretary J. R. Kline reported briefly concerning actions of the Council and President Morse spoke about the present status with respect to military service of teachers and students of mathematics. Lieutenant C. C. Hurd described the training program at the United States Coast Guard Academy at New London, Connecticut.

On Wednesday at 2 P.M., Professor W. L. Ayres of Purdue University gave an address entitled Transformations with periodic properties. At 3:15 P.M., a symposium on The applicability of mathematical statistics to war efforts, was held jointly with the Institute of Mathematical Statistics. Addresses were given on Statistical prediction with special reference to the problem of tolerance limits by Professor S. S. Wilks of Princeton University, and $O n$ the nature of mathematical statistics in quality control by Dr. W. E. Deming of the U. S. Department of Commerce. The discussion leaders were Professor J. H. Curtiss of Cornell University, and Dean Walter Bartky of the University of Chicago.

The presiding officers for the sessions of short papers were: Analysis, Tuesday morning, Professor R. E. Langer; Algebra, Geometry, and Topology, Tuesday morning, Professor A. W. Tucker; Mathematical Statistics (a joint session with the Institute of Mathematical Statistics), Tuesday afternoon, Professor C. C. Craig; Topology, Thursday morning, Professor R. L. Wilder; Analysis and Applied Mathematics, Thursday morning, Professor Gabor Szegö. Professor J. R. Kline presided at the general session at 2 P.M., Wednesday and Lieutenant Colonel L. E. Simon at the symposium held jointly with the Institute of Mathematical Statistics.

Headquarters for the meeting were in Main Building. Rooms in this building were made available to members of the three organizations and their guests.

On Wednesday evening in Main Building there was a dinner for members of the Society, the Association, and the Institute. Professor H. S. White was toastmaster. President H. N. MacCracken of Vassar College gave an address of welcome. Professor R. E. Langer spoke of the impetus being given to mathematics in our secondary 
schools and colleges. Professor W. T. Reid presented a resolution of thanks to the President, the Department of Mathematics, the Local Committee, and everyone concerned at Vassar College, for the competent arrangements and cordial hospitality. The resolution was adopted unanimously. Following the dinner members of the Department of Music of Vassar College gave an excellent concert in Belle Skinner Hall.

On Monday afternoon in Ely Hall, a tea was given for members of the three organizations and their guests by the Department of Mathematics of Vassar College.

The Council met on Tuesday, September 8, at 8:00 P.M. in Main Building at Vassar College.

The Secretary announced the election of the following twenty persons to membership in the Society:

Dr. William D. Berg, State University of Iowa;

Mr. Howard Jesse Eckweiler, New York University;

Mr Joseph Owen Evans, Shreveport Aeronautical Institute, Shreveport, La.;

Mother Ethelyn Fox, Barat College of the Sacred Heart, Lake Forest, Ill.;

Mr. William J. Fry, Naval Research Laboratory, Washington, D. C.;

Mr. Cecil Hastings, Jr., University of Florida;

Mr. Cyrus Giles Hill, J. G. Wray and Co., Engineers, Chicago. Ill.;

Professor Truman Lee Kelley, Graduate School of Education, Harvard University;

President Eugene McDermott, Geophysical Service, Inc., Dallas, Tex.;

Dr. Leonard McFadden, Virginia Polytechnic Institute;

Mr. Frank Albert McMahon, Brooklyn College Evening Session;

Dr. Henry Malin, College of the City of New York;

Mr. William Edwin Manring, American Cyanamid and Chemical Corporation, New York, N. Y.;

Professor Philip B. Norman, Tusculum College, Greenville, Tenn.;

Professor Edward Russell Stabler, Hofstra College, Hempstead, N. Y.;

Dr. Domina Eberle Spencer, Massachusetts Institute of Technology;

Dr. Robert L. Swain, University of Wisconsin;

Mr. Hsio-Fu Tuan, Princeton University;

Mr. David Freeman Votaw, Jr., Princeton University;

Mr. Hyman Joseph Zimmerberg, University of Chicago.

It was also announced that Texas Technological College, Lubbock, Texas, had been elected to institutional contributing membership.

Professor Michel Plancherel of the Ecole Polytechnique Fédérale, Zurich, Switzerland, was admitted to the Society in accordance with the reciprocity agreement with the Swiss Mathematical Society.

The following appointments by President Marston Morse were reported: as representative of the Society at the Inaugural Ceremony of the Polish Institute of Arts and Sciences in America on May 15, 1942, Professor C. C. MacDuffee; as representative of the Society at the inauguration of Harry Noble Wright as President of The College 
of the City of New York on September 30, 1942, Professor C. C. MacDuffee; as a member of the Committee on Places of Meetings, to replace Professor P. R. Rider (term to expire December 31, 1944), Professor E. W. Chittenden.

It was announced that reports were sent in August to the Carnegie Corporation and Rockefeller Foundation regarding their grants to Mathematical Reviews. The Secretary also announced that the problem of the importation of journals from European Axis and Axiscontrolled countries had been solved for Mathematical Reviews. Under an arrangement concluded with the American Library Association, Mathematical Reviews is permitted to purchase all the journals to which it has been subscribing, thus continuing full coverage of the mathematical literature of the scientific world.

Certain invitations to give invited addresses were announced: Professor J. L. Synge for the October, 1942, meeting in New York; Professors Harry Bateman, L. M. K. Boelter, J. Holmboe, and H. U. Sverdrup for the November, 1942, meeting in Los Angeles; Professor Deane Montgomery for the 1942 Annual Meeting in New York; and Professor Emil Artin for the April, 1943, meeting in Chicago.

On recommendation of the Committee on Places of Meetings (Professor A. B. Coble, chairman), the Annual Meeting of 1943 was set at Cleveland, Ohio, in connection with the meetings of the American Association for the Advancement of Science. Times and places of meetings during 1943 were set as follows: in New York City on February 27; in New York City on April 23-24; in Chicago on April 23-24; at Stanford University on April 24; in Corvallis, Oregon, on June 16-17 (with A.A.A.S.); in New York City on October 30.

Because of travel difficulties and other problems created by the war, the Council voted to withdraw its acceptance of the invitation to meet at the University of Colorado for the Summer Meeting of 1943. It is the intention of the Society to meet at Colorado as soon as conditions permit. Arrangements are under way for holding a summer meeting at a more centrally-located institution.

The eighteenth Josiah Willard Gibbs Lecture is to be given by Professor Harry Bateman at the Annual Meeting of 1943 in Cleveland, Ohio.

On recommendation of the Colloquium Editorial Committee, the Council voted to invite Professor Einar Hille to deliver a series of Colloquium Lectures in 1944.

Professor Marston Morse was appointed representative on the National Research Council for a period of three years beginning July, 1943. 
The Secretary announced the provisions of the will of the late Dr. Robert Henderson who was, for many years, a Trustee of the Society and deeply interested in all of its activities. The Society will share the income of his estate with two other beneficiaries, and, upon the death of the other legatees, the Society will receive the full principal of the estate for the Endowment Fund.

President Morse appointed the following committees: Committee on the Award of the Bôcher Prize, to be awarded at the Annual Meeting of 1943, for papers in Analysis published during the period 1938-1942, Professors T. H. Hildebrandt (chairman), Philip Franklin, and John von Neumann; Committee to Select Gibbs Lecturers for 1944 and 1945, Professors J. H. Van Vleck (chairman), B. O. Koopman, and E. J. McShane.

The Council voted to continue the practice, inaugurated two years ago, of presenting on the ballot twice as many candidates for vicepresident and for members-at-large of the Council as there are positions to be filled. It was also voted that the ballot continue to have a place where members may present suggestions for trustees, officers, and members of the Council, these suggestions to be considered by the Nominating Committee for the following year. Members are urged to make more use of this method of placing names before the Nominating Committee.

Titles and cross references to the abstracts of papers read are given below. The papers were read as follows: papers 1-6 in the section for Analysis on Tuesday morning; papers 7-12 in the section for Algebra, Geometry, and Topology on Tuesday morning; papers 13-22 in the section for Mathematical Statistics on Tuesday afternoon; papers 23-27 in the general session Wednesday morning; papers 28-31 in the section for Topology Thursday morning; papers 32-34 in the section for Analysis and Applied Mathematics Thursday morning; and papers 35-89, whose abstract numbers are followed by the letter $t$, were read by title. Dr. Spencer was introduced by Professor D. J. Struik, Mr. Kincaid by Dr. D. W. Hall, Miss Marth by Professor Francis Regan, and Dr. Schwerdtfeger by Dr. Peter Scherk. Paper 2 was presented by Professor Clarkson, paper 3 by Professor Adams, paper 5 by Dr. Salem, paper 9 by Professor MacLane, paper 17 by Dr. Mann, paper 21 by Dr. Struik, paper 23 in the absence of Professor Whitney by Professor Saunders MacLane, paper 24 by Professor Hille, paper 30 by Dr. Samelson, and paper 33 by Dr. Poritsky.

1. M. E. Munroe: On the finite dimensionality of certain Banach spaces. (Abstract 48-7-241). 
2. J. A. Clarkson and Paul Erdös: On the approximation of continuous functions by polynomials. (Abstract 48-9-258.)

3. C. R. Adams and A. P. Morse: On approximating certain integrals by sums. (Abstract 48-9-255.)

4. Otto Szász: On the partial sums of Fourier series at points of discontinuity. (Abstract 48-9-264).

5. Raphael Salem and D. C. Spencer: The influence of gaps on density of integers. (Abstract 48-7-245.)

6. P. C. Rosenbloom: The zeros of the partial sums of power series representing entire functions. (Abstract 48-11-321.)

7. C. J. Thorne: An Appell subset. (Abstract 48-9-265.)

8. Domina E. Spencer: Geometric figures in affine space. (Abstract 48-9-281.)

9. Saunders MacLane and Samuel Eilenberg: Functions of groups as generalized tensors. (Abstract 48-11-341.)

10. Gordon Pall: The weight of an n-ary genus of quadratic forms. (Abstract 48-11-307.)

11. Saly R. R. Struik: Axiomatics of affine geometry. (Abstract 48-11-334.)

12. R. P. Dilworth: On the decomposition theory of modular lattices. (Abstract 48-11-301.)

13. Henry Scheffé: On the theory of testing composite hypotheses with one constraint. (Abstract 48-7-248.)

14. Jacob Wolfowitz: On the consistency of a class of non-parametric statistics. (Abstract 48-11-338.)

15. E. J. Gumbel: Graphical controls based on serial numbers. (Abstract 48-9-283.)

16. D. S. Villars: Significance tests for multivariate distributions. (Abstract 48-9-289.)

17. H. B. Mann and Abraham Wald: On the choice of the number of class intervals in the application of the chi-square test. (Abstract 48-9-285.)

18. F. E. Satterthwaite: Generalized Poisson distribution. (Abstract 48-9-286.)

19. L. A. Aroian: The relationship of Fisher's z distribution to Student's $t$ distribution. (Abstract 48-9-282.)

20. Abraham Wald: On a statistical problem arising in the classification of an individual in one of two groups. (Abstract 48-11-337.)

21. Saly R. R. Struik and Miriam van Waters: Modern statistical methods in penology. (Abstract 48-9-288.)

22. T. N. E. Greville: Regularity of label-sequences under configuration transformations. (Abstract 48-11-335.) 
23. Hassler Whitney: The self-intersections of an $M^{n}$ in $E^{2 n}$. (Abstract 48-9-297.)

24. Einar Hille and Gabor Szegö: On the complex zeros of the Bessel functions. (Abstract 48-11-313.)

25. Edward Kasner: The inverse problem of dynamics. (Abstract 48-9-279.)

26. L. W. Cohen: Integration on hypersurfaces. (Abstract 48-11311.)

27. W. T. Reid: Some results on the growth of solutions of differential systems. (Abstract 48-11-319.)

28. D. W. Hall: On a partial solution of a problem of J. R. Kline. (Abstract 48-9-290.)

29. J. W. T. Youngs: $A$ note on separation axioms and their application in the theory of a locally connected topological space. (Abstract 48-11-347.)

30. Deane Montgomery and Hans Samelson: Groups transitive on spheres. (Abstract 48-9-293.)

31. F. B. Jones: A characterization of the sphere. (Abstract 48-11340.)

32. Vladimir Morkovin: On the deflection of anisotropic thin plates. (Abstract 48-9-272.)

33. W. R. Foote, Hillel Poritsky and J. J. Slade: The motion of a rotor with unequal shaft flexibilities mounted in bearings of unequal flexibility. (Abstract 48-11-327.)

34. Stefan Bergman: Operators in the theory of partial differential equations and their application. II. (Abstract 48-9-271.)

35. G. E. Albert: Criteria for the closure of systems of orthogonal functions. (Abstract 48-9-256-t.)

36. Reinhold Baer: Rings with duals. (Abstract 48-7-230-t.)

37. Stefan Bergman: Operators in the theory of differential equations and their application. I. (Abstract 48-9-270-t.)

38. H. K. Brown: The resolution of boundary value problems by means of the finite Fourier transformation. (Abstract 48-7-246-t.)

39. Leonard Carlitz: Representation of a polynomial in certain forms. (Abstract 48-11-299-t.)

40. Leonard Carlitz: Some formulas for the composition of numerical functions. (Abstract 48-11-300-t.)

41. H. S. M. Coxeter: A geometrical background for the description of de Sitter's world. (Abstract 48-9-273-t.)

42. J. J. DeCicco: The application of turbine geometry to the inverse problem of dynamics. (Abstract 48-9-275-t.) 
43. C. J. Everett: Affine geometry of vector spaces over rings. (Abstract $48-7-247-t$.)

44. Willy Feller: On some geometric inequalities. (Abstract 48-11312-t.)

45. B. H. Gere and David Zupnik: On the construction of curves of constant width. (Abstract 48-9-276-t.)

46. W. H. Gottschalk: On k-to-1 mappings. (Abstract 48-7-249-t.)

47. O. G. Harrold: $A$ higher dimensional analogue of a theorem of plane topology. (Abstract 48-11-339-t.)

48. Mark Kac: On the average number of roots of a random algebraic equation. (Abstract 48-9-284-t.)

49. Mark Kac: On the distribution of values of trigonometric sums with linearly independent frequencies. (Abstract 48-9-259-t.)

50. Edward Kasner and J. J. DeCicco: Transformation theory of isogonal trajectories of isothermal families. (Abstract 48-9-280-t.)

51. A. J. Kempner: Periodic decimals to any base, and quadratic residues. (Abstract 48-11-305-t.)

52. W. M. Kincaid: On non-cut sets of locally connected continua. (Abstract 48-9-291-t.)

53. D. M. Krabill: On extension of Wronskian matrices. (Abstract 48-11-316-t.)

54. D. H. Lehmer: Recurrence formulas for certain divisor functions. (Abstract 48-9-252-t.)

55. Walter Leighton and W. J. Thron: On the convergence of continued fractions to meromorphic functions. (Abstract 48-7-237-t.)

56. Lee Lorch: Lebesgue constants for Borel summability of Fourier series. (Abstract 48-11-317-t.)

57. R. G. Lubben: Mappings of spaces II Frêchet on completely regular spaces. (Abstract 48-9-292-t.)

58. Szolem Mandelbrojt and F. E. Ulrich: On a generalization of the problem of quasi-analyticity. (Abstract 48-7-239-t.)

59. Ella Marth: On Garvin's F-series. Preliminary report. (Abstract 48-9-260-t.)

60. Karl Menger: Projective generalization of metric geometry. I. (Abstract 48-11-330-t.)

61. Karl Menger: Projective generalizations of metric geometry. II. (Abstract 48-11-331-t.)

62. Josephine M. Mitchell: On double Sturm-Liouville series. (Abstract 48-9-261-t.)

63. Deane Montgomery and Hans Samelson: Groups transitive on the $n$-dimensional torus. (Abstract 48-9-294-t.) 
64. Deane Montgomery and Leo Zippin: A class of transformation groups in $E_{n}$. (Abstract 48-9-295-t.)

65. R. L. Moore: Concerning a continuum and its boundary. (Abstract 48-11-342-t.)

66. R. L. Moore: Concerning intersecting continua. (Abstract 4811-343-t.)

67. Marston Morse: Unstable minimal surfaces bounded by a rectifiable contour. (Abstract 48-7-240-t.)

68. K. L. Nielsen and B. P. Ramsay: On particular solutions of linear partial differential equations. (Abstract 48-9-262-t.)

69. Gordon Pall: The distribution of integers represented by binary quadratic forms. (Abstract 48-11-306-t.)

70. C. N. Reynolds: A calculus of finite topological differences with application to the four color problem. (Abstract 48-11-344-t.)

71. Mary De Pazzi Rochford: Completely non-integrable pfaffians. (Abstract 48-7-242-t.)

72. Mary De Pazzi Rochford: Differentiability properties of certain functions of two variables. (Abstract 48-7-243-t.)

73. Raphael Salem: On a theorem of Zygmund. (Abstract 48-9263-t.)

74. Henry Scheffé: On the ratio of the variances of two normal populations. (Abstract 48-9-287-t.)

75. A. R. Schweitzer: On a class of ordered $(n+1)$-ads relevant to the algebra of logic. III. (Abstract 48-11-333-t.)

76. H. Schwerdtfeger: $A$ complete parametrization of the symplectic group. (Abstract 48-7-233-t.)

77. Max Shiffman: Unstable extremal surfaces for double integral problems in the calculus of variations. (Abstract 48-11-322-t.)

78. Dorothy M. Smiley: A note on Burnside's problem. (Abstract 48-9-253-t.)

79. M. F. Smiley: A comparison of algebraic, metric, and lattice betweenness. (Abstract 48-5-190-t.)

80. Saly R. R. Struik: Emmy Noether and Maria Gaetana Agnesi, two outstanding women mathematicians. (Abstract 48-11-332-t.)

81. H. S. Thurston: The solution of p-adic equations. (Abstract 489-254-t.)

82. A. D. Wallace: Separation spaces. II. (Abstract 48-7-251-t.)

83. Hermann Weyl: On Hodge's theory of harmonic integrals. (Abstract 48-9-266-t.)

84. Hassler Whitney: Complexes of manifolds. (Abstract 48-9296-t.) 
85. Hassler Whitney: Differentiability of the remainder term in Taylor's formula. (Abstract 48-9-267-t.)

86. Hassler Whitney: Note on differentiable even functions. (Abstract 48-9-268-t.)

87. Hassler Whitney: The general type of singularity of a set of $2 n-1$ smooth functions of $n$ variables. (Abstract 48-9-269-t.)

88. Hassler Whitney: The singularities of an $M^{n}$ in $E^{2 n-1}$. (Abstract 48-9-298-t.)

89. G. T. Whyburn: Homotopy classes of mappings into the circle. (Abstract 48-11-346-t.)

T. R. Hollcroft, Associate Secretary 